\title{
Drug Susceptibility of Brazilian Strains of Mycobacterium bovis Using Traditional and Molecular Techniques
}

\author{
Patrícia M Parreiras, Francisco CF Lobato*, Andréa P Alencar**, Telma de Figueiredo, \\ Harrison M Gomes, Neio Boéchat***, Andrey P Lage*, Ronnie A Assis*, \\ Márcia AS Pereira, Patrícia R Souza**, Pedro MPC Mota**, Philip N Suffys/+
}

\begin{abstract}
Laboratório de Biologia Molecular Aplicada à Micobactérias, Departamento de Medicina Tropical, Instituto Oswaldo CruzFiocruz, Av. Brasil 4365, 21040-900 Rio de Janeiro, RJ, Brasil *Escola de Veterinária, UFMG, Belo Horizonte, MG, Brasil

**Laboratório Regional de Apoio Animal, Ministério da Agricultura, Pecuária e Abastecimento, Pedro Leopoldo, MG, Brasil ***Unidade de Pesquisa em Tuberculose, Instituto de Doenças de Tórax, HUCFF, UFRJ, Rio de Janeiro, RJ, Brasil
\end{abstract}

Transmission of Mycobacterium bovis from cattle to humans has been reported and can cause tuberculosis (Tb) and a problem in certain risk populations. Therefore, knowledge of resistance of $\mathrm{M}$. bovis towards antibiotics used for therapy of human $\mathrm{Tb}$ could help avoiding cure delay and treatment cost increase when dealing with drug resistant organisms. We therefore evaluated the susceptibility of $\mathrm{M}$. bovis isolates towards streptomycin, isoniazide, rifampicin, ethambutol, and ethionamide, the first line antibiotics for human Tb. Therefore, 185 clinical samples from cattle with clinical signs of tuberculosis were processed and submitted to culturing and bacterial isolates to identification and drug susceptibility testing using the proportion method. Among 89 mycobacterial strains, 65 were identified as $\mathrm{M}$. bovis and none were resistant to any of the antibiotics used. Confirmation of present results by future studies, enrolling a large number of isolates and designed to properly represent Brazilian regions, may favor the idea of using isoniazide preventive therapy as part of a Tb control strategy in special situations. Also, nucleic acids from bacterial isolates were submitted to rifoligotyping, a recently described reverse hybridization assay for detection of mutations causing resistance towards rifampicin. Concordance between the conventional and the molecular test was 100\%, demonstrating the use of such methodology for rapid evaluation of drug susceptibility in $\mathrm{M}$. bovis.

Key words: Mycobacterium bovis - drug susceptibility - isoniazide - rifoligotyping

Tuberculosis ( $\mathrm{Tb})$ is caused by infection with $\mathrm{Myco}$ bacterium tuberculosis and is one of most severe infectious diseases. During the last decade, control of $\mathrm{Tb}$ turned more complicated because of decreasing socioeconomic conditions, the human immunodeficiency virus pandemic and the spread of drug (DR) and multi-drug resistant (MDR) M. tuberculosis strains. One third of the world population is infected and over 100,000 new $\mathrm{Tb}$ cases are reported each year in Brazil (WHO 1993). Infection with $M$. bovis followed by $\mathrm{Tb}$ has been reported mainly in cattle, wild and domestic pigs, primates (Nolte \& Metchock 1995) and in humans, disease symptoms are indistinguishable from that caused by M. tuberculosis and is therefore generally treated in the same way. Bovine tuberculosis is much more frequent in developing than in developed countries, and although in most latter, the disease was considered under control (Ferreira Neto \& Bernardi 1997, Mota \& Lobato 1998), reports on resurgence of bovine tuberculosis has been demonstrated

Financial support: Papes III/Fundação Oswaldo Cruz, Projeto Instituto Milênio, Pronex 661028/1998-4, INCO-DEV Concerted Action Project ICA4-CT-2001-10087

${ }^{+}$Corresponding author. Fax: +55-21-2270.9997. Email: psuffys@ioc.fiocruz.br

Received 8 April 2004

Accepted 14 September 2004
(Collins et al. 1994). In Brazil, the mean national prevalence of $M$. bovis infection in cattle $\mathrm{Tb}$ was estimated at $1.3 \%$ for the period 1989 to 1998 but this can increase to $15 \%$ in farms with some automated form of milk production (Belchior 2001).

Successful control of human tuberculosis should be accompanied by control of animal tuberculosis because transfer of $M$. bovis to humans has been reported, both through respiratory route and consumption of contaminated meat and dairy products. Especially farmers and veterinarians are at elevated risk to get infected with $M$. bovis while HIV-infection increases risk for Tb development after infection with $M$. tuberculosis or $M$. bovis (O'Reilley \& Daborn 1995). According to WHO (1993), infection with $M$. bovis is responsible for about $5 \%$ of human Tb cases in Brazil, suggesting the importance of better control of transmission from cattle to man.

M. bovis is naturally resistant to pyrazinamide (Cepanzo 1988) and usually susceptible to most antibiotics used to treat human $\mathrm{Tb}$, caused either by infection with M. tuberculoisis or M. bovis. The main control of bovine $\mathrm{Tb}$ is through "tuberculinization test and slaughter" strategy but due to the financial burden of this procedure, uncontrolled, and unregistered use of antibiotics, mainly isoniazide, is frequently occurring for treatment of cattle with signs of Tb infection in Brazil (Mota 2003). Having in mind that monotherapy results quickly in the generation of drug-resistant bacilli and their possible transmission to humans, an evaluation of drug susceptibility of $M$. bovis strains is warranted to understand the magni- 
tude of influence of the transmission of DR or MDR $M$. bovis strains on treatment of human $\mathrm{Tb}$.

The molecular basis of resistance has been clarified to a different extent for the antituberculosis drugs. In the case of rifampicin, detection of mutations in a small fragment of the rpoB gene predicts drug susceptibility in about 95\% of the M. tuberculosis strains and although the mechanism of resistance seams identical in M. bovis, no data are available on distribution of mutation frequency in this species. Recently, a reverse hybridization-based assay for detection of these mutations was shown to be highly sensitive and specific for human isolates of $M$. tuberculosis (Morcillo et al. 2002) but again, no M. bovis isolates have been included in the study.

We therefore evaluated susceptibility of isolates of M. bovis of bovine origin towards the five mostly used first line antituberculous drugs. Also, the efficiency of the rifoligotyping assay was evaluated in a retrospective way on these isolates of $M$. bovis.

\section{MATERIALS AND METHODS}

Collection of sample and processing for culture During the period of 2001-2002, we performed an exploratory, transversal study by collecting tuberculous caseum lesions from 185 different animals of cattle, mainly from the state of Minas Gerais and some other regions of Brazil, including Santa Catarina, Mato Grosso do Sul, Amazonas, Goiás, Paraíba, and São Paulo. Sample collection occurred under supervision of the Federal Inspection of the state of Minas Gerais and the material sent frozen or in ice in a plastic recipient to the Tuberculosis Laboratory of the Regional Laboratory of the Ministry of Agriculture. Among these, 56 had had been isolated in the field and 129 from slaughterhouses; no information was available regarding PPD skin test evaluation. The material was decontaminated according to Mota (1985), in brief, by incubating in 6\% sulfuric acid during $30 \mathrm{~min}$ and followed by centrifugation at $500 \mathrm{~g}$ for $15 \mathrm{~min}$. The pellet was washed twice in $0.85 \%$ saline solution and distributed in four tubes containing Stonebrink medium. Cultures were incubated at $37^{\circ} \mathrm{C}$ and observed weekly until being discarded after 4 weeks.

Identification and drug susceptibility testing - These tests were performed at same laboratory according to procedures were according to Cepanzo (1988). In summary, 65 cultures were obtained and evaluated for production of niacian, nitrate reduction capacity, susceptibility to 100 $\mathrm{mg} / \mathrm{ml}$ pyrazinamide in Löwenstein-Jensen medium, hydrolysis of Tween and catalase activity at room temperature and at $68^{\circ} \mathrm{C}$. Drug susceptibility was performed in Stonebrink medium containing sodium glutamate and without pyruvate. Antibiotics (Sigma Chemicals Co., US) were added separately in different concentrations $(4 \mu \mathrm{g} / \mathrm{ml}$ streptomycin, $40 \mu \mathrm{g} / \mathrm{ml}$ rifampicin, $2 \mu \mathrm{g} / \mathrm{ml}$ ethambutol, 20 $\mu \mathrm{g} / \mathrm{ml}$ ethionamide, and $0.2 \mu \mathrm{g} / \mathrm{ml}$ isoniazide) and considered resistant when either 10\% (streptomycin and ethionamide) or $1 \%$ (others) of the amount of colonies observed in the sample without drug was counted in the antibiotic containing vial. The drug susceptible strain $M$. tuberculosis H37Rv was included as a control for antibiotic activity.
Mutation detection using the RIFO-assay - The procedure was performed at the Leprosy Laboratory of the Oswaldo Cruz Institute at the Oswaldo Cruz Foundation (Fiocruz) in Rio de Janeiro, Brazil. Initially, nucleic acid extraction was performed on a fraction of the culture as described by Van Embden et al. (1993). Basically, a loop full of bacteria were submitted to digestion with lysozyme and proteinase $\mathrm{K}$, followed by treatment with $\mathrm{CTAB}$ and chloroform/isoamylalcohol and precipitation with isopropanol. For detection of the rpoB genotype, rifoligotyping was performed basically as described by Morcillo et al. (2002). Therefore, a fragment from 1497 to 1653 of the rpoB gene was amplified using $100 \mathrm{ng}$ of primers TR10A (5'-CGC CGC GAT CAA GGA GT-3') and biotinylated TR11A (5'-ACG TCG CGG ACC TCC A-3') in a $25 \mu 1$ reaction volume containing $1 \mathrm{U}$ of Taq polymerase (Gibco BRL, US) and buffer, $0.2 \mathrm{mM}$ of each dNTP and $10 \mathrm{ng}$ of target DNA. Cycling was performed by incubating for $3 \mathrm{~min}$ at $95^{\circ} \mathrm{C}$; followed by a touch-down PCR $\left(2^{\circ} \mathrm{C}\right.$ per step $)$ from two cycles of $20 \mathrm{~s} 95^{\circ} \mathrm{C}, 30 \mathrm{~s} 65^{\circ} \mathrm{C}, 30 \mathrm{~s} 72^{\circ} \mathrm{C}$ to two cycles of $20 \mathrm{~s} 95^{\circ} \mathrm{C}, 30 \mathrm{~s} 57^{\circ} \mathrm{C}, 30 \mathrm{~s} 72^{\circ} \mathrm{C}$, and more 25 steps of 20 s $95^{\circ} \mathrm{C}, 30$ s $55^{\circ} \mathrm{C}, 30 \mathrm{~s} 72^{\circ} \mathrm{C}$. Amplification was verified on a $2 \%$ agarose gel and product used in the reverse line blot hybridization assay basically as described by Morcillo et al. (2002) except that we included an oligonucleotide (5'-G CTG TTG GGG TTG ACC-3') for hybridization with the mutant allele at codon 522 (TCG $\rightarrow$ TTG). Herefore, a membrane (Biodyne $\mathrm{C}$ membrane, Pall Biosupport) was activated by incubation with $16 \%$ (wt/vol) 1-ethyl-3-(3dimethylaminopropyl) carbodiimide (Sigma) for $15 \mathrm{~min}$. The oligonucleotides with aminolink were diluted in 0.5 $\mathrm{M} \mathrm{NaHCO}_{3}(\mathrm{pH} 8.4$ ) at a concentration ranging from 12.5 to $200 \mathrm{pmol} / 150 \mu \mathrm{l}$ (Morcillo et al. 2002), applied on the membrane using a Miniblotter MN45 (Isogen, the Netherlands) and after $1 \mathrm{~min}$ incubation at RT, the membrane was inactivated with $100 \mathrm{mM} \mathrm{NaOH}$ for $10 \mathrm{~min}$ and washed in $2 \times$ SSPE containing $0.1 \%$ SDS for $10 \mathrm{~min}$ at $50^{\circ} \mathrm{C}$. For hybridization, $10 \mathrm{ml}$ of amplicon was diluted in $150 \mu 12 \mathrm{x}$ $\mathrm{SSPE} / 0.1 \% \mathrm{SDS}$, heat denatured at $100^{\circ} \mathrm{C}$ for $10 \mathrm{~min}$, chilled on ice and applied on the membrane using the miniblotter, in a perpendicular direction to the immobilized oligonucleotides. Hybridization occurred for $45 \mathrm{~min}$ at $50^{\circ} \mathrm{C}$ and the membrane was washed twice in $2 \times \mathrm{SSPE} / 0.5 \% \mathrm{SDS}$ for 10 min at $5^{\circ} \mathrm{C}$, followed by incubation in $10 \mathrm{ml} 2 \times \mathrm{SSPE} /$ $0.5 \%$ SDS containing $1.25 \mathrm{U}$ streptavidin-peroxidase conjugate (Amersham Pharmacia Biotech) for $30 \mathrm{~min}$ at $42^{\circ} \mathrm{C}$. This was followed by washing in $2 \mathrm{X}$ SSPE/0.5\%SDS, twice for $10 \mathrm{~min}$ at $42^{\circ} \mathrm{C}$ and twice for $5 \mathrm{~min}$ at RT. Hybridization to the membrane was visualized by enhanced chemiluminescence (ECL; Amersham Pharmacia Biotech) and exposure to a light sensitive film (Hyperfilm ECL, Amersham). As controls for the rifoligotyping procedure, one drug sensitive and six rifampicin resistant (one 531-TGG and five $531 \mathrm{TTG}$ ) strains of $M$. tuberculosis were included in an experiment. Interpretation of the hybridization patterns was performed by two persons and yielded the same conclusion.

\section{RESULTS}

From 185 clinical samples, 89 mycobacterial isolates were obtained of which 24 were rapid growing organisms 
not belonging to the $M$. tuberculosis Complex. No information on identity of these isolates was available at the time of this study. Biochemical characteristics, including nitrate reduction, absence of niacin, hydrolysis of Tween and catalase activity at $68^{\circ} \mathrm{C}$ and most importantly, natural resistance to pyrazinamide, demonstrated that 65 isolates were $M$. bovis. This observation was confirmed by the generation of $M$. bovis genotypes after submitting the isolates to spoligotyping (data not shown).

All isolates of $M$. bovis were successfully submitted to conventional susceptibility testing for the five antibiotics; none was resistant against any of the drugs tested.

Of the 65 isolates of M. bovis, 50 could be submitted to rifoligotyping and as partly demonstrated in the Figure, all generated the wild-type rpoB hybridization pattern. Two independent persons performed the interpretation of the genotypes. The rifampicin resistant and sensitive $M$. tuberculosis control strains generated the expected genotype patterns, demonstrating that the rifoligotyping experiments were executed under appropriate conditions and that the assay is accurate (kappa $=1)$.

\section{DISCUSSION}

There exists an increasing concern in the scientific community about the increase in both human and bovine $\mathrm{Tb}$ and the more frequent observation of drug resistant isolates of $M$. bovis and M. tuberculosis (Langenegger et al. 1981, 1991). In Brazil, three among 200 (1.5\%) isolates from Tb patients were MDR M. bovis strains (Corrêa \& Corrêa 1974) and recently, Leite and Lage (1999) reported to evaluate better the problem of drug resistant $M$. bovis strains in bovine $\mathrm{Tb}$. Although none of the 65 isolates identified as $M$. bovis were resistant to any of the five anti-Tb drugs tested, we are aware that our study has limited statistical power. Indeed, estimating prevalence as $1.5 \%$, a greater number of isolates $(n=536)$ would be tested to achieve a $95 \%$ confidence interval. Therefore, future studies are needed to definitively clarify the question of $M$. bovis anti-Tb drug resistance in Brazil.

The need to monitor incidence and transmission of drug resistant $\mathrm{Tb}$ has been suggested by WHO since 1993, when the disease was considered again a serious treat to human health, partly because of the increase in HIV and development of MDR strains of M. tuberculosis (Blázquez et al. 1997). Multi-drug resistant Tb can also be caused by infection with MDR M. bovis strains in HIV positive individuals (Blázquez et al. 1997) and AIDS increases Tb development, also after infection with $M$. bovis (O'Reilly \& Daborn 1995). This increases concern about transmission of MDR $M$. bovis strains in a human risk population and transfer of $M$. bovis strains from cattle to human is occurring with a certain frequency among individuals with more intense contact (Mota 2003). Furthermore, the presence of viable $M$. bovis was recently demonstrated in livestock specimens and milk obtained in Brazil (Leite et al. 2003). Although transmission of MDR strains from cattle to man has to our knowledge not being reported, evaluation of drug susceptibility of $M$. bovis strains is important, not only for estimating such risk but also to understand the effect of uncontrolled use of antibiotics in cattle. Especially in the states of Minas Gerais and São Paulo, use of isoniazide for treatment of dairy cattle has become routine, principally because of the collaboration between farmers and large corporations for the purchase and distribution of the drug on a large scale (Belchior 2001).

Such lack of resistance, particularly towards isoniazide, orients health professionals in relation to correct treatment of humans infected by $M$. bovis and on the risk-free use of isoniazide for treatment of infected animals, when performed under strict supervision of veterinary official of Ministry of Agriculture. There is an ongoing discussion in Brazil on the use of antituberculous drugs for cattle treatment: arguments against treatment are the possible

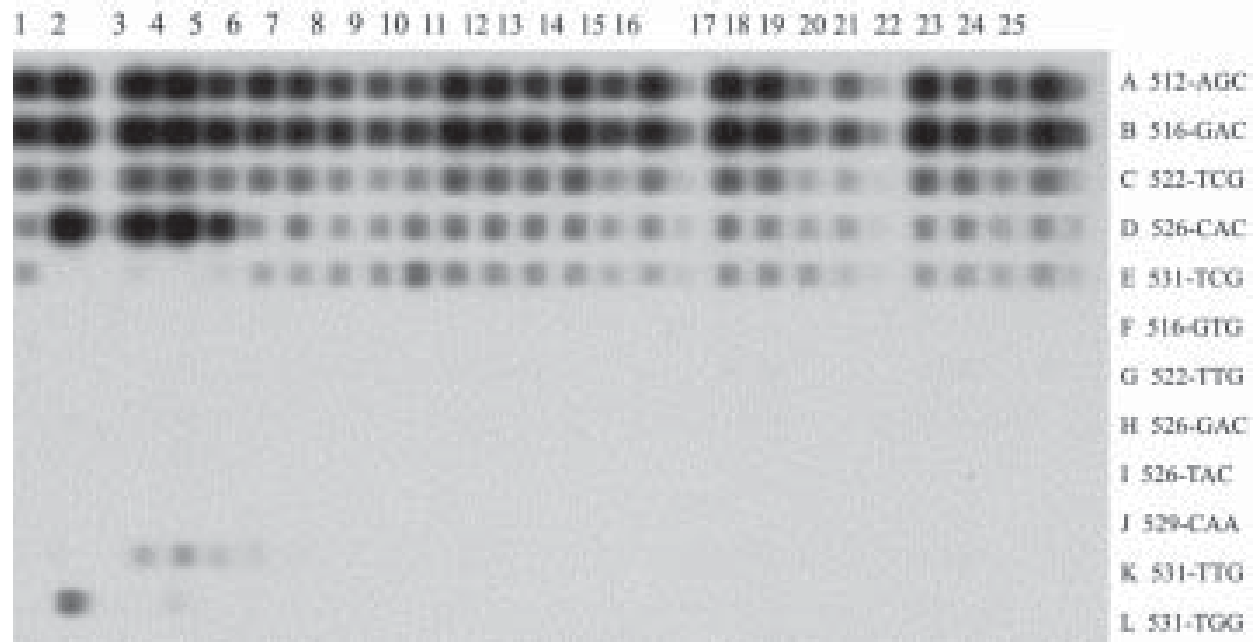

Hybridization patterns obtained after rifoligotyping of Brazilian strains of Mycobacterium tuberculosis and M. bovis. In this experiment, six strains of M. tuberculosis (lane 1-6), including one rifampicin sensitive (lane 1) and five rifampicin resistant (lanes 2-6) and 19 rifampicin susceptible strains of $M$. bovis (lanes 8-25) were hybridized to a membrane containing five probes specific for wild type sequences of part of the rроB gene (lanes A-E) and seven probes covering the same regions but specific for the mutated form of the alleles (lanes F-L). The wild type or mutated codons are marked on the figure (lane A-L). 
increase of transmission from animals that are treated but not cured when "test and slaughter" is replaced by generalized treatment; also, selection of drug resistant strains by use of monotherapy or inadequate treatment is an argument. In favor of treatment are those who believe that "test and slaughter" is not popular in regions where $\mathrm{Tb}$ prevalence is high, stimulating frauds and omission of information. Fortunately, studies on treatment results in Brazil are promising as studies by Langenegger et al. (1981, 1991) demonstrated cure rates using isoniazide in highly infected farms was $93 \%$ using as a cure criterion reversion of sensibility to tuberculin testing during a period of more than two years. Diminished or even lack of tuberculin reaction after isoniazide treatment had also been described by Leite and Lage (1999). More recently, Mota (2003) demonstrated, using microbiologic examination and allergy desensibilization, a cure rate of $99 \%$ among naturally infected animals in the region of Zona da Mata, Minas Gerais. Besides that, this study demonstrated a considerable increase in milk production among treated animals, being one of the contributing factors for decreasing the concentration of isoniazide in milk for human consumption (Leite \& Lage 1999). Considering cure rates, lack of circulation of isoniazide resistant M. bovis strains and decreased uptake of isoniazide in milk by pasteurization, isoniazide treatment under strict supervision seems an alternative for "test and slaughter".

In this study, we also used a recently developed reverse hybridization based assay, rifoligotyping, for detection of resistance towards rifampicin in M. tuberculosis (Morcillo et al. 2002). This assay is based on the detection of point mutations present in a small region (hot spot) of the rpoB gene and has not been evaluated on $M$. bovis strains. All 50 isolates that were characterized as sensitive towards rifampicin gave the sensitive rpoB genotype after submission to the hybridization procedure. This is no surprise because it has been described that the mechanism of resistance in M. tuberculosis is shared by M. tuberculosis, M. africanum, and M. leprae (Williams et al. 1994) and that the rроB sequence is identical for the organisms belonging to the M. tuberculosis Complex (Kim et al. 1999), even when considering a highly polymorphic region of this gene (Lee et al. 2003). Although no rifampicin resistant $M$. bovis isolates were included so we cannot conclude on the sensitivity of rifoligotyping in this species, the sequence data from literature and the correct hybridization of the sensitive strains with all five probes for the wild $r p o B$ sequence strongly support the idea that rifoligotyping will be a quick assay for large scale susceptibility typing in M. bovis.

\section{REFERENCES}

Belchior AP 2001. Prevalência, Distribuição Regional e Fatores de Risco da Tuberculose Bovina em Minas Gerais, MSc Thesis, Escola de Medicina Veterinária, UFMG, Belo Horizonte.

Blázquez J, Monteros LEE, Samper S, Martín C, Guerrero A, Cobo J, Embden JV, Baquero F, Gómez-Mampaso E 1997. Genetic characterization of multidrug-resistant Mycobacte- rium bovis strains from a hospital outbreak involving human immunodeficiency virus-positive patients. J Clin Microbiol 35: 1390-1393.

Cepanzo - Centro Panamericano de Zoonosis 1988. Bacteriologia de la Tuberculosis, Organización Mundial de la Salud, Buenos Aires, p. 36-39.

Collins DM, Radford AJ, Lisle GW, Billman-Jacobe H 1994. Diagnosis and epidemiology of bovine tuberculosis using molecular biological approaches. Vet Microbiol 40: 83-94.

Corrêa CN, Corrêa WM 1974. Tuberculose humana por bacilo bovino em São Paulo. Arq Inst Biol São Paulo 43: 131-134.

Ferreira Neto JS, Bernardi FO 1997. O controle da tuberculose bovina. Hig Alim 11: 9-13.

Kim BJ, Lee SH, Lyu MA, Kim SJ 1999. Identification of mycobacterial species by comparative sequence analysis of the RNA polymerase gene (rpoB). J Clin Microbiol 37: 1714-1720.

Langenegger J, Langenegger CH, Oliveira J 1981. Tratamento da tuberculose bovina com isoniazida. Pesq Vet Bras 1: 1-6.

Langenegger J, Leite GO, Oliveira Jr J 1991. Tratamento intermitente da tuberculose bovina com isoniazida. Pesq Vet Bras 11: 55-59.

Lee H, Bang HE, Bai GH, Cho SN 2003. Novel polymorphic region of the rpoB gene containing Mycobacterium speciesspecific sequences and its use in identification of mycobacteria. J Clin Microbiol 41: 2213-2218.

Leite CQ, Anno IS, Leite SR, Roxo E, Morlock GP, Cooksey RC 2003. Isolation and identification of mycobacteria from livestock specimens and milk obtained in Brazil. Mem Inst Oswaldo Cruz 98: 319-323.

Leite, RMH, Lage, AP 1999. Controle da tuberculose em bovinos da raça Sândi pelo tratamento com isoniazida: avaliação e análise de custos. Cienc Vet Trop 2: 21-28.

Morcillo N, Zumarraga M, Alito A, Dolmann A, Schouls L, Cataldi A, Kremer K, Van Soolingen D 2002. A low cost, home-made, reverse-line blot hybridization assay for rapid detection of rifampicin resistance in Mycobacterium tuberculosis. Int J Tuberc Lung Dis 6: 959-965.

Mota PMPC 1985. Estudo da Esofagostomose como Fator Predisponente de Reações Alérgicas Inespecíficas da Tuberculose Bovina, MSc Thesis, Escola de Medicina Veterinária, UFMG, Belo Horizonte.

Mota PMPC 2003. Tuberculose Bovina: Diagnóstico e Controle, PhD Thesis, Escola de Medicina Veterinária, UFMG, Belo Horizonte

Mota PMPC, Lobato FCF 1998. Tuberculose bovina: uma revisão. In AP Lage, FCF Lobato, PMPC Mota, VSP Gonçalves (eds), Atualização em Tuberculose Bovina, UFMG, Belo Horizonte, p. 3-34.

Nolte FS, Metchock B 1995. Mycobacterium. In PR Murray, Manual of Clinical Microbiology, 6 ed., ASM, Washington, p. $400-437$.

O'Reilly LM, Daborn CJ 1995. The epidemiology of Mycobacterium bovis infections in animals and man: a review. Tuberc Lung Diseases 76 (Suppl.): 1-46.

Van Embden JDA, Cave MD, Crawford JT 1993. Strain identification of Mycobacterium tuberculosis by DNA fingerprinting: recommendations for a standardized methodology. J Clin Microbiol 31: 406-409.

Williams DL, Waguespack C, Eisenach K, Crawford JT 1994. Characterization of rifampin resistence in pathogenic mycobacteria. Antimicrob Agents Chemother 38: 2380-2386.

WHO-World Health Organization 1993. Report of the WHO meeting of zoonotic tuberculosis (Mycobacterium bovis) Technical Note, Geneva, 27 pp. 